\title{
The critical role of imaging navigation and guidance in transcatheter aortic valve implantation
}

\author{
Pencilla Lang, BEng, ${ }^{\mathrm{a}, \mathrm{b}}$ Terry M. Peters, PhD, ${ }^{\mathrm{a}, \mathrm{b}}$ Bob Kiaii, MD, FRCSC, ${ }^{\mathrm{a}, \mathrm{c}}$ and Michael W. A. Chu, MD, \\ FRCSC $^{\mathrm{a}, \mathrm{b}, \mathrm{c}}$
}

Transcatheter aortic valve implantation (TAVI), an innovative stent-based technique for delivery of a bioprosthetic valve, has seen remarkable growth since 2002 and has resulted in a paradigm shift in treatment options for elderly patients with aortic stenosis. Although there have been major advancements in transcatheter valve design and endovascular access routes, TAVI still relies largely on single-plane fluoroscopy for intraoperative navigation and guidance, with only gross structures visible. Patient outcomes have improved with experience; however, early complications still occur and are commonly associated with limited intraoperative imaging and suboptimal valve positioning. We discuss these concepts and describe how a greater emphasis on imaging research could significantly reduce the current perioperative morbidity and mortality of TAVI and lead to a better controlled, more accurate, and safer procedure.

Reparative heart procedures have traditionally required open-chest heart surgery, relying on large incisions, the heart-lung machine, direct visualization, and manual tissue manipulation. Percutaneous, guidewire-based approaches that have been developed to perform coronary artery angioplasty and stenting often depend on single or biplane fluoroscopic imaging. These techniques have evolved to address more complex structural heart defects, such as atrial septal defects and valvular stenosis. Transcatheter aortic valve implantation (TAVI) is a less-invasive alternative in which a bioprosthetic valve is delivered on a catheter through the femoral artery (transfemoral) or left ventricular apex (transapical) to the aortic annulus, displacing the native valve and replacing its function. This innovative, stent-based approach removes the need for a large incision and avoids the risks of a conventional operation while providing a less-invasive solution to the common problem of aortic stenosis. Since 2002, more than 20,000 TAVI procedures have been performed with good outcomes. ${ }^{1}$ Recently, the Randomized Placement of Aortic Transcatheter Valve

\footnotetext{
From the Robarts Research Institute, ${ }^{\mathrm{a}}$ the Department of Biomedical Engineering, ${ }^{\mathrm{b}}$ and the Division of Cardiac Surgery, ${ }^{\mathrm{c}}$ Department of Surgery, University of Western Ontario, London, Ontario, Canada.

Disclosures: Authors have nothing to disclose with regard to commercial support.

Received for publication Jan 21, 2012; accepted for publication Feb 3, 2012; available ahead of print March 9, 2012.

Address for reprints: Michael W. A. Chu, MD, FRCSC, B6-106 University Hospital, London Health Sciences Centre, 339 Windermere Rd, PO Box 5339, London,

Ontario, Canada N6A 5A5 (E-mail: mwachu@gmail.com).

J Thorac Cardiovasc Surg 2012;143:1241-3

$0022-5223 / \$ 36.00$

Copyright (c) 2012 by The American Association for Thoracic Surgery doi:10.1016/j.jtcvs.2012.02.010
}

(PARTNER) trial has demonstrated significantly better survival after TAVI treatment than after medical therapy in nonsurgical patients and similar survivals after TAVI and surgical replacement in high-risk patients. ${ }^{2,3}$ Although there have been major advances in transcatheter valve design, most TAVI procedures still rely solely on singleplane fluoroscopic imaging for intraoperative guidance.

\section{THE PROBLEM}

Despite the success and growth of TAVI thus far, significant complications remain, including death, stroke, valve malposition, embolism, coronary obstruction, heart block requiring permanent pacemaker, paravalvular leak, and secondary nephrotoxicity from contrast use. ${ }^{4}$ Most of these complications may be related to inadequate image guidance and suboptimal valve positioning, because single-plane fluoroscopy provides only gross imaging of the aortic valve, rendering the surgeon blind to surrounding structures. As a result, valve implantation often requires some degree of calculated faith in avoiding injury to hidden adjacent structures. Poor alignment of the valve with respect to the aortic annulus may result in valve malposition once deployed or in embolism of the device. Similarly, positioning the valve too deeply may cause atrioventricular block and the need for a permanent pacemaker. Coronary obstruction may be caused by positioning the valve directly in front of the coronary ostia or in such a manner that the displaced native valve occludes the coronary ostia. Some cases of paravalvular leak may also be related to poor positioning of the stent with respect to calcium on the native leaflets, which would prevent the stent from deploying fully. ${ }^{5}$ Finally, use of multiple contrast fluoroscopic images can increase the risk of secondary nephrotoxicity.

Safe positioning of a transcatheter valve requires both the anatomic structures of the aorta and the valved stent to be visible intraoperatively. Although most centers use preoperative computed tomography (CT) to assess patient candidacy, intraoperative guidance consists of aortography for positioning and transesophageal echocardiography for functional assessment. ${ }^{6,7}$ Neither of these modalities is optimal for guidance. Aortography provides good stent delineation but lacks 3-dimensional context and provides only limited views of the aortic valve and coronary ostia. In addition, repeated contrast exposure has been reported to cause acute kidney injury in $11 \%$ to $24 \%$ of patients. ${ }^{8-11}$ Transesophageal echocardiography can provide real-time 
visualization of both the aortic root and new prosthesis but suffers from poor spatial resolution and artifacts introduced by the metal stent and heavy calcification of the stenotic valve, making the images difficult to interpret with certainty. ${ }^{12,13}$ Although preoperative CT provides good anatomic visualization for procedure planning and prosthesis selection, these landmarks cannot be used for intraoperative guidance because they do not provide context for intraoperative tools.

\section{CURRENT TAVI INVESTMENTS}

Seemingly inordinate efforts and exorbitant research funding have been invested in the design of second- and third-generation transcatheter valves, and many of these efforts have focused on self-alignment, miniaturization, and the ability to reposition a valve after initial deployment. ${ }^{14}$ There are more than 20 different devices at various stages of development and testing, with thus far a single device, the Edwards SAPIEN valve (Edwards Lifesciences LLC, Irvine, Calif), having received US Food and Drug Administration approval. ${ }^{14}$ Although many of these devices will no doubt improve patient outcomes and reduce procedural risk, there is a clear paucity of research into improvements in intraoperative visualization and guidance.

\section{CURRENT TAVI IMAGING PROGRESS}

Recent research has focused on the use of additional intraoperative 3-dimensional imaging to address visualization deficits. Kempfert and colleagues ${ }^{15}$ used the DynaCT system (Siemens AG, Erlangen, Germany), an intraoperative cone-beam CT overlaid on a fluoroscopic image, to provide anatomic context. The DynaCT system constructs a segmented aortic root from rotational angiography and automatically detects landmarks, such as the coronary ostia. The segmented image is superimposed on the real-time fluoroscopic image. The images are used as a guidance tool during transapical aortic valve implantation and to select an optimal C-arm angulation for fluoroscopy. Recent results in 50 patients have demonstrated positional accuracy of the coronary ostia, as displayed on the fluoroscopic image, of $4.8 \mathrm{~mm} .{ }^{16}$ Although this technique represents an improvement, the $\mathrm{CT}$ model remains static and does not allow real-time intraoperative guidance. Horvath and associates ${ }^{17}$ used intraoperative magnetic resonance imaging to guide placement of the stent, resulting in successful implantation in porcine subjects. Such intraoperative 3-dimensional imaging is not widely available, however, and it is very expensive. Hybrid operating suites capable of acquiring rotational angiography cost between US $\$ 1.2$ and \$2.0 million, and the base costs of intraoperative magnetic resonance imaging can exceed US \$5.3 million, with significant additional operating and maintenance costs. ${ }^{18}$

\section{RATIONALE AND HYPOTHESIS}

We believe that the most efficacious way to improve TAVI outcomes and reduce the risk of complications is to improve intraoperative imaging to allow optimal valve positioning. Improved visualization of the TAVI prosthesis and calcium within the aortic root may eliminate valve malposition, eliminate embolization and coronary obstruction, reduce the risk of paravalvular leak and heart block, and reduce the need for contrast.

Proper visualization, through improved intraoperative imaging, would reduce the reliance on self-aligning devices to ensure optimal valve positioning within the aortic root. This provides the physician more control over valve positioning, allowing the valve position to be optimized intraoperatively and in real time in accordance with patientspecific factors. Reducing physician uncertainty regarding valve position in the root with better imaging would also reduce the need to resheath and reposition the device multiple times.

There remain several important unsolved problems in image guidance for TAVI. Most importantly, there is a need for concurrent, real-time, intraoperative visualization of the stent and aortic root geometry in 3 dimensions. This imaging needs to be both affordable and easy to integrate into existing work flow. An ideal system would be intuitive to use and require little specialized knowledge to operate or interpret. There is also a need for the ability to predict calcium fracture patterns and motion on the basis of preoperative imaging and to visualize calcium motion intraoperatively to allow compensation or adjustment of valve positioning. Many new developing technologies, including computerbased aortic root models and augmented imaging, demonstrate great potential in addressing these challenges. ${ }^{19,20}$ A greater emphasis on research in imaging technology for TAVI could lead to a better controlled, safer procedure with fewer complications.

\section{References}

1. Piazza N, van Mieghem N, Tzikas A, Lange R, de Jaegere P, Serruys PW. Interpreting the current data on transcatheter aortic valve implantation: a difficult task. Eur Heart J. 2010;12(Suppl):E41-5.

2. Leon MB, Smith CR, Mack MJ, Miller DC, Moses JW, Svensson LG, et al. Transcatheter aortic-valve implantation for aortic stenosis in patients who cannot undergo surgery. N Engl J Med. 2010;363:1597-607.

3. Smith CR, Leon MB, Mack MJ, Miller DC, Moses JW, Svensson LG, et al. Transcatheter versus surgical aortic valve replacement in high-risk patients. $N$ Engl J Med. 2011;364:2187-98.

4. Masson JB, Kovac J, Schuler G, Ye J, Cheung A, Kapadia S, et al. Transcatheter aortic valve implantation: review of the nature, management, and avoidance of procedural complications. JACC Cardiovasc Interv. 2009;2:811-20.

5. Bombien R, Hümme T, Schunke M, Lutter G. Percutaneous aortic valve replacement: computed tomography scan after valved stent implantation in human cadaver hearts. Eur J Cardiothorac Surg. 2009;36:592-4.

6. Chu M, Borger M, Mohr F, Walther T. Transcatheter heart valve replacement: update. CMAJ. 2010;182:791-5.

7. Delgado V, Ng AC, Shanks M, van der Kley F, Schuijf JD, van de Veire NR, et al. Transcatheter aortic valve implantation: role of multimodality cardiac imaging. Expert Rev Cardiovasc Ther. 2010;8:113-23. 
8. Van Linden A, Kempfert J, Rastan AJ, Holzhey D, Blumenstein J, Schuler G, et al. Risk of acute kidney injury after minimally invasive transapical aortic valve implantation in 270 patients. Eur J Cardiothorac Surg. 2001;39:835-43.

9. Aregger F, Wenaweser P, Hellige GJ, Kadner A, Carrel T, Windecker S, et al. Risk of acute kidney injury in patients with severe aortic valve stenosis undergoing transcatheter valve replacement. Nephrol Dial Transplant. 2009;24: 2175-9.

10. Strauch JT, Scherner MP, Haldenwang PL, Pfister R, Kuhn EW, Madershahian N, et al. Minimally invasive transapical aortic valve implantation and the risk of acute kidney injury. Ann Thorac Surg. 2010;89:465-70.

11. Bagur R, Webb JG, Nietlispach F, Dumont E, De Larochellière R, Doyle D, et al. Acute kidney injury following transcatheter aortic valve implantation: predictive factors, prognostic value, and comparison with surgical aortic valve replacement. Eur Heart J. 2010;31:865-74.

12. Jayasuriya C, Moss RR, Munt B. Transcatheter aortic valve implantation in aortic stenosis: the role of echocardiography. J Am Soc Echocardiogr. 2011;24:15-27.

13. Chin D. Echocardiography for transcatheter aortic valve implantation. Eur J Echocardiogr. 2009;10:i21-9.

14. Thielmann M, Kahlert P, Konorza T, Erbel R, Jakob H, Wendt D. Current developments in transcatheter aortic valve implantation techniques. Herz. 2011;36: 696-705.
15. Kempfert J, Rastan A, Noettling A, et al. Perioperative dynact for improved imaging during transapical aortic valve implantation. Circulation. 2010;122: A16869.

16. Kempfert J, Rastan A, Noettling A, John M, van Linden A, Blumenstein J, et al Perioperative DynaCT for improved imaging during transapical aortic valve implantation. Circulation. 2010;122:A16869.

17. Horvath KA, Mazilu D, Guttman M, Zetts A, Hunt T, Li M. Midterm results of transapical aortic valve replacement via real-time magnetic resonance imaging guidance. J Thorac Cardiovasc Surg. 2010;139:424-30.

18. American Hospital Association. AHA policy research technical report. Adopting technological innovation in hospitals: who pays and who benefits? Chicago: The Association; 2006.

19. Ionasec RI, Voigt I, Georgescu B, Wang Y, Houle H, Vega-Higuera F, et al Patient-specific modeling and quantification of the aortic and mitral valves from 4-D cardiac CT and TEE. IEEE Trans Med Imaging. 2010;29: 1636-51.

20. Lang P, Chen EC, Guiraudon GM, Jones DL, Bainbridge D, Chu MW, et al Feature-based US to CT registration of the aortic root. In: Wong KH, Holmes DR III. Medical imaging 2011: visualization, image-guided procedures, and modeling. Proceedings of SPIE, vol 7964. Lake Buena Vista, Fla; February 13-15, 2011. Bellingham, WA: SPIE; 2011:79641G. 